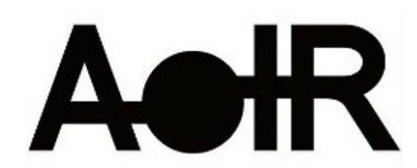

Selected Papers of \#AoIR2021:

The 22nd Annual Conference of the

Association of Internet Researchers

Virtual Event / 13-16 Oct 2021

\title{
Staying in Their Lanes: Issue Ownership in the 2016 and 2020 U.S. Presidential Campaigns on Facebook and Twitter
}

\author{
Jeff Hemsley \\ Syracuse University \\ Jennifer Stromer-Galley \\ Syracuse University \\ Patrícia Rossini \\ University of Liverpool \\ Alexander Smith \\ Syracuse University

\section{Introduction}

Scholarly interest in the use of social media by political campaigns has been consistently growing as digital platforms are becoming increasingly central for candidates to communicate and engage with the public (Stromer-Galley, 2019). Recent presidential primaries in the United States saw unprecedented numbers of candidates competing for the nomination on the Republican and on the Democratic side. This paper takes up some classic conceptualizations of campaign messaging from the television era--issue campaigning--and applies it to analyze the ways campaigns rhetorically communicate their candidacy on their free social media accounts on Facebook and Twitter, where they communicate with supporters, the public, and the news media. When it comes to television ads, researchers have found that the majority of campaign communication was focused on the issues (Johnson and Kaid, 2002). Would such findings be true in the digital era? In this study, we examine to what extent candidates post about issues and policy matters on Facebook and Twitter.

Prior research has identified issue-ownership across partisan lines, with Republicans seen to focus on issues such as taxes and national defense, and Democrats more likely to focus on social issues and welfare (Petrocik, Benoit \& Hansen, 2003). Given the complexities of the primary race, with candidates aiming to differentiate themselves

Suggested Citation (APA): Hemsley, J., Stromer-Galley, J., Rossini, P., Smith, A. (2021, October). Staying in Their Lanes: Issue Ownership in the 2016 and 2020 U.S. Presidential Campaigns on Facebook and Twitter. Paper presented at AolR 2021: The 22nd Annual Conference of the Association of Internet Researchers. Virtual Event: AolR. Retrieved from http://spir.aoir.org. 
within their own party, we ask whether the candidates in both parties engage in creating "lanes" by owning specific policy topics. We also investigate the context in which candidates discuss the issues in terms of advocacy and attack-that is, do they refer to issues to advocate for their own competency, or are issues used to attack opponents?

\section{Methods}

We use supervised machine-learning to analyze all messages (Facebook and Twitter) posted by 17 Republicans and 19 Democrats during the 2016 and 2020 U.S.

Presidential Elections. The data for the 2016 election was collected between September 1, 2015 and November 9th, 2016. The date range for 2020 was September 1, 2019 to November 4th, 2020. Candidate posts were first categorized by message type using supervised machine-learning. Using a multi-label classifier, posts were initially categorized as advocacy, attack, image, and issue. The performance for these models has an overall F1 score of 0.67 or higher for Twitter and of 0.72 or higher for Facebook.

Next, we used a lexicon approach to classify candidate posts on twelve different political topics (covid, economic, education, environment, foreign policy, governance, health, immigration, military, safety, social and cultural, social programs). We validated our lexicons by comparing machine vs. human tagging on a random sample. We found agreement of $75 \%$ or better on each topic. Using data visualization and chi-square tests, we examined the volume of posts to see what topics the candidates of the different parties tended to use.

\section{Results}

When looking at all attack or advocacy posts on Facebook and Twitter across both electoral cycles, it is noticeable that Democrats are more likely to post about the issues on social media. Shifting to differences in specific issues, we find that Republicans and Democrats talk about significantly different topics on social media, (ChiSq $=3034.5, p<$ 0.0001). As it can be seen on Figure 1, Democrats are overall more likely to post on a range of issues, such as the economy, social and cultural issues, social programs, health, safety, education, and the environment. Republicans tend to have a narrower range of policy topics, with more emphasis on about issues, foreign policy, and immigration.

However, the primaries in 2016 and 2020 were distinct, with Republicans facing a crowded field in the former and Democrats in the latter. To this point, distinctions between the two primary cycles, and particularly in 2020 , may reflect how issue ownership patterns change when intra-party competition is one-sided. Comparing 2016 to 2020, there are differences in the topics 'owned' by each party, with Republicans more likely than Democrats to post about the economy, safety, and social and cultural issues in 2016.

We also note that some issues were largely absent from the discussion in 2016, such as health and governance. These might reflect two dynamics that were unique to 2020: the Covid-19 global pandemic, which raised awareness and gave more centrality to the issue of healthcare, and the broader discussion of the electoral processes, voting, and 
corruption, which were prominent topics given the reliance on mail-in voting and Trump's impeachment by the House of Representatives.

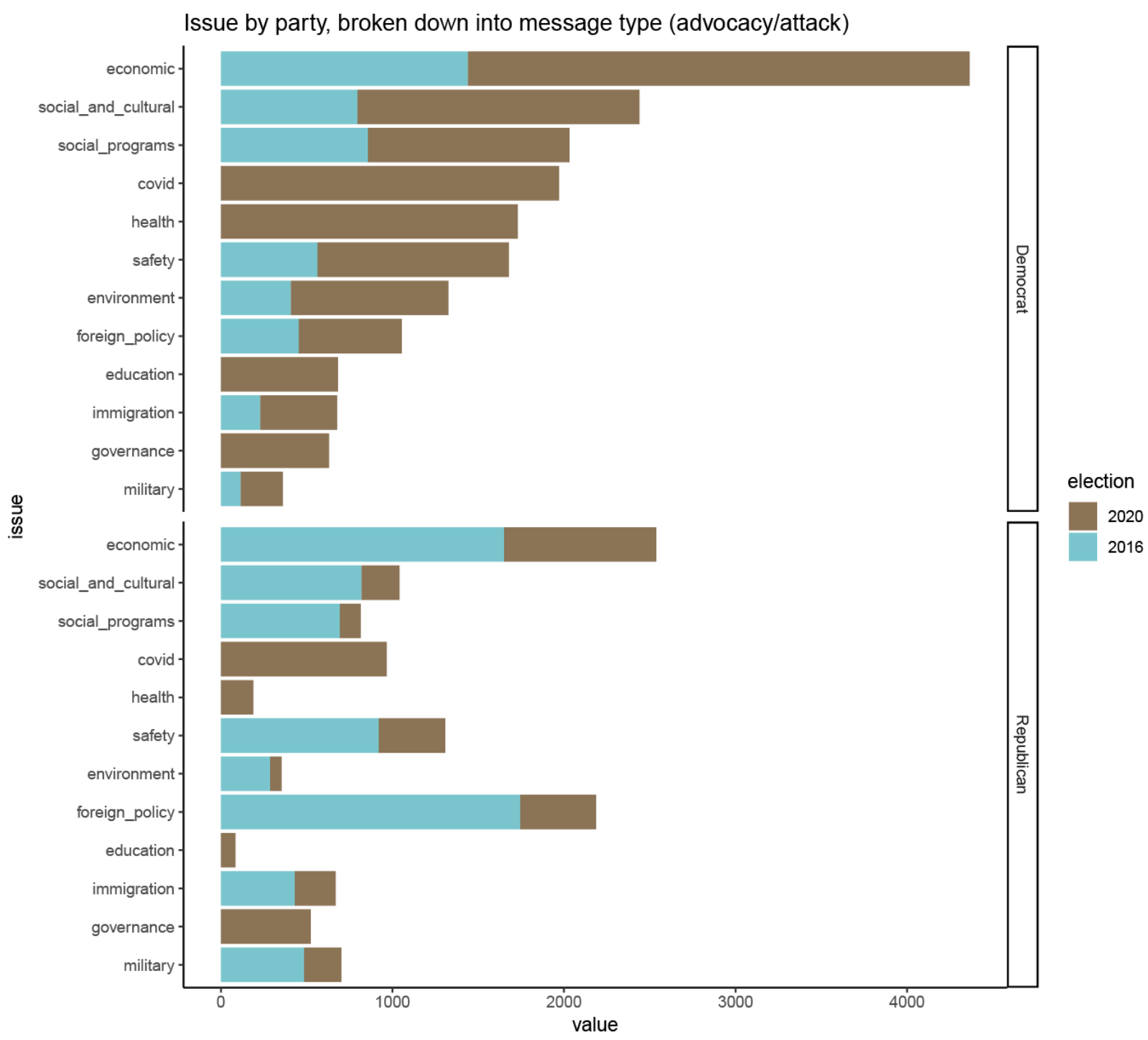

Figure 1. Total posts per issue by party and year

We examine the extent to which each party relied on advocacy messages, that is, positive posts about the candidate's plans and competencies, and attacks, which are mainly negative and directed to a candidate's opponents, including the news media, to criticize them. Messages could also feature both types-what can be described as a contrast message (Johnson and Kaid, 2002).

As shown in Figure 2, candidates from both parties predominantly used advocacy messages to talk about most issues, with few exceptions: for instance, on the topic of governance, which did not appear in 2016, Donald Trump posted more attacks and contrast messages than advocacy messages, while Democrats advocated more. Republicans were more prominently using attack and contrast messages in most topics, with the exception of the military. When Democrats go on the attack, they are more 
inclined to use contrast messages-surpassing Republicans in this category in the topics of Covid-19, foreign policy, immigration, and the military.

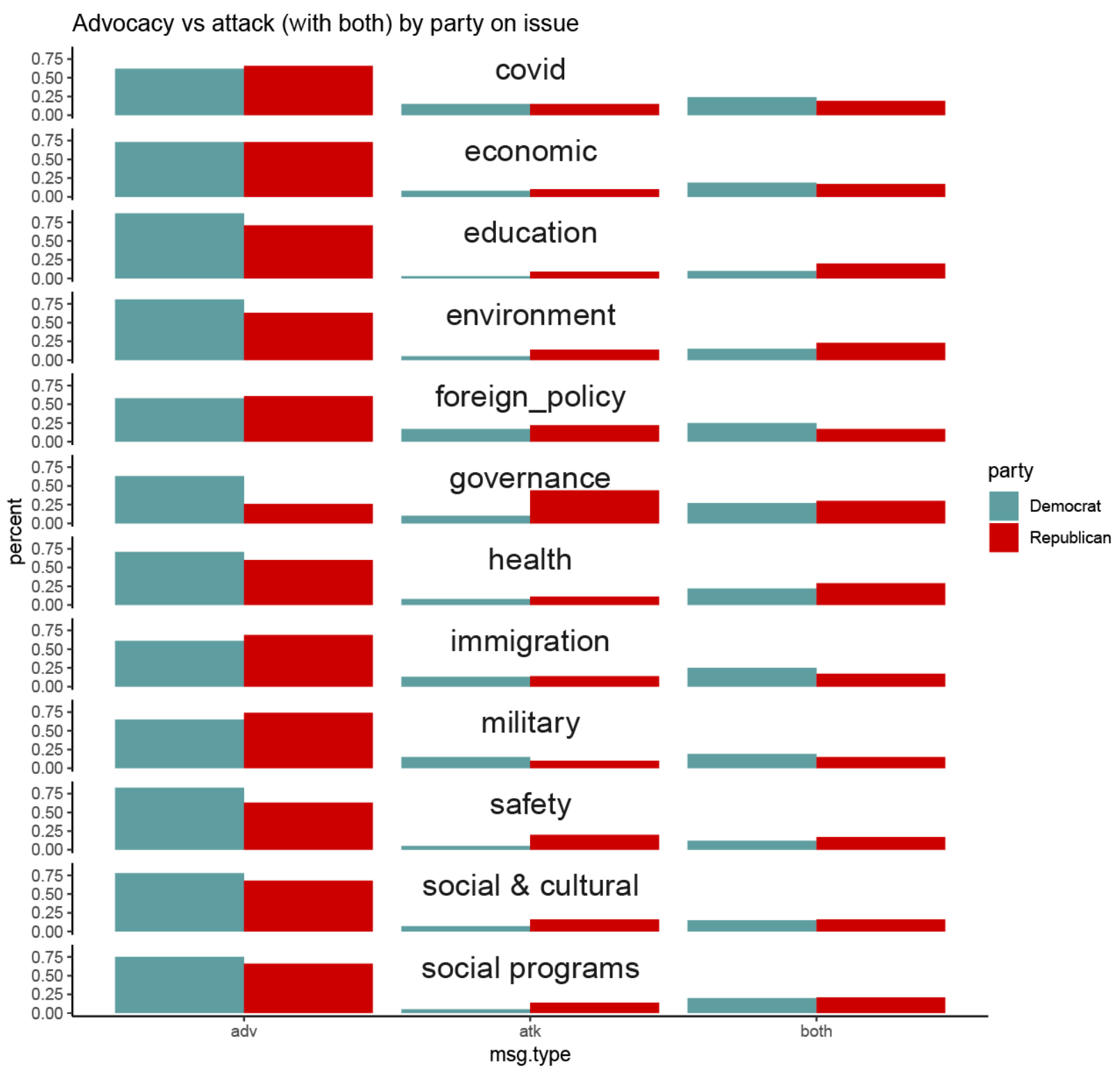

Figure 2. Proportion of attack, advocacy and contrast messages per party and issue

\section{Conclusion}

This study examines how candidates use social media to talk about political issues across the 2016 and 2020 presidential campaign. We find first that there is issuefocused posting on social media. We also find that parties demonstrate significantly different patterns of topic ownership, with Republicans owning topics such as the military and foreign affairs, and Democrats owning social programs and social and cultural issues. This suggests that the parties continue to own policy matters that they historically were aligned with. However, in the case of the economy, these dynamics are sensitive to electoral contexts: even though Democrats were overall more likely to post 
about issues, Republicans posted more messages than Democrats on this topic in 2016, while in 2020 issues around health were of central focus of both parties.

Moreover, the topic of governance, rarely of much interest to politicians or the public, was of central importance in $\mathbf{2 0 2 0}$ given the challenges of voting given the global pandemic.

\section{References}

Johnston, A., \& Kaid, L. L. (2002). Image ads and issue ads in U.S. presidential advertising: Using videostyle to explore stylistic differences in televised political ads from 1952 to 2000. Journal of Communication, 52, 281-300

Petrocik, J. R., Benoit, W. L., \& Hansen, G. J. (2004). Issue ownership and presidential campaigning, 1952-2000. Political Science Quarterly, 118 (4), 599-626.

Stromer-Galley, J. 2019). Presidential campaigning in the Internet age (2nd Ed.). Oxford University Press. 